\title{
Prevalence of work-related musculoskeletal disorders in agricultural farmers of Bhaktapur District, Nepal
}

\author{
Prakash Kumar Mahto ${ }^{1}$, Bhupal Gautam, BPT ${ }^{2}$ \\ ${ }^{1}$ Prakash Kumar Mahto, MPT (Musculoskeletal), Physiotherapist, Kathmandu Medical College, \\ Kathmandu, Nepal. \\ ${ }^{2}$ Bhupal Gautam, BPT. Helpline, Health and Physio Center, Bhaktapur
}

\section{ABSTRACT}

Background: Work-related musculoskeletal disorders are present in a range of occupations. This is confirmed from a number of studies done around the world. However, few attempts have been done to document the presence of musculoskeletal disorders in occupational diseases in Nepal and there are hardly any studies done to see musculoskeletal disorders in farmers of Nepal. Nepal is an agricultural country and traditional practices in farming are adopted demanding a lot on the manual work.

Objectives: Aim of this study is to find out the prevalence of musculoskeletal disorders in Bhaktapur district of Nepal.

Methods: This is a descriptive cross-sectional study design. A convenience sample of 246 farmers from Bhaktapur district, Nepal aged between 24-65 years, were included in the study. The Nordic musculoskeletal questionnaire was a tool adapted to measure MSDs in the farmers. Descriptive analysis of data was done.

Results: Farmers $(n=246)$ reported pain in all the nine areas of the body mentioned in the questionnaire. More than $70 \%$ of farmers have some kind of musculoskeletal disorders. However, six major areas of pain were identified as: Neck-31(12.6 \%), Shoulder-26(10.6\%), Elbow-30(12.2\%), Low back- 89(36.2\%), Knee- 53(21.5\%) and ankle $32(13 \%)$.

Conclusion: The prevalence of musculoskeletal disorders in farmers is very high. Lack of awareness about the MSDs and improper knowledge of ergonomics causes the problems.

Key words:

DOI: https://doi.org/10.3126/ijosh.v8i1.22922

\section{Introduction}

A n estimated 1.3 billion workers are engaged in agriculture production worldwide. Half of the total world labor force and a great number of agriculture workers are found in Asia. ${ }^{1}$ Agricultural work has long been recognized as one of the most hazardous occupations to human health both in developing and developed countries. ${ }^{2,3}$ According to international labor organization (ILO), around 160 million work-related illness per year occur around the world, in which workrelated musculoskeletal disorders (WMSDs) have a

\section{Corresponding Author}

Prakash Kumar Mahto

MPT (Musculoskeletal), Physiotherapist,

Kathmandu Medical College, Kathmandu, Nepal.

E-mail: mprakashk@hotmail.com prominent role in terms of occupational health and also economic. $^{3}$

A lot of occupational diseases, accidents, and workrelated disorders are common in farmers. ${ }^{4}$ These include musculoskeletal disorders, respiratory disease, noise-induced hearing loss, pesticide-related illness, and increased reporting of cancer cases. ${ }^{5,6}$ Among these problems, musculoskeletal disorders are frequent of all occupational non-fatal injuries and illness for farmers. ${ }^{5,7}$ Nwuba and Kaul also examined the working posture of the Nigerian hoe farmer. They reported that workers developed strains in the low back, which were injurious to their health. ${ }^{5} \mathrm{~A}$ study in Finland showed that musculoskeletal disorders compared with a control population, farmers had twice as much incidence of musculoskeletal disorders. ${ }^{8}$ Musculoskeletal disorders

() 2018 IJOSH All rights reserved 
are defined as a group of disorders that affect the musculoskeletal system including the nerves, tendons, muscles, and joints and supporting structures such as inter-vertebral discs. ${ }^{9}$ Musculoskeletal disorders could result in pain, injury, illness, poor quality of life and reduced productivity. ${ }^{10}$ They are the main source of disability and less work time. ${ }^{11}$

Ergonomic (Human Factor) is the scientific discipline concerned with the understanding of the interactions among humans and other elements of a system and the profession that applies theory, principles, data, and methods to design in order to optimize human well being and overall system performance. In the design of work and everyday life situations, the focus of ergonomics is a man. Unsafe, unhealthy, uncomfortable or inefficient situations at work or in everyday life are avoided by taking account of the physical and psychological capabilities and limitations of a human. ${ }^{12}$ The field of human factors and ergonomics has largely focused on the so-called normal population ranging between the ages of 20 to 65 years. ${ }^{13}$

Problems of musculoskeletal pain and/or discomfort are associated with physical disability, and severely affect the health-related quality of life (QoL). The disorder takes on a more serious dimension when it becomes chronic; nearly 25 percent of the affected adults are identified as having chronic Musculoskeletal (MS) impairment, which is equally prevalent in both developed as well as developing countries. ${ }^{14,15}$ The studies conducted worldwide to determine the nature of chronic MSD among farmers, documents low back pain (LBP) as the most common MSD. The incidence of chronic low back pain MS impairment among farmers, pain, and disorder prevalent for 1-year or more, was to the extent of 47 percent in Sweden, 23 percent in Finland, and 37 percent in the US. The major workrelated risk factors associated with LBP have been identified as poor/awkward work postures, bending, lifting and physically strenuous work. ${ }^{16,17,18}$

\section{Methodology}

This cross-sectional study was carried out during 2018 February among farmers in Bhaktapur District, randomly selected from among all the rural and urban areas of Bhaktapur District (Nepal).

A self-administered questionnaire, together with an invitation letter and information about the study, was distributed to each agricultural worker by hand. The researcher made an appointment a few days later to come back to collect the completed questionnaire. A pilot study was carried out in 15 farmers before the main study to find out the reliability of the questionnaire.

\section{Inclusion Criteria:}

Age: above 24 years below 65; all males and females; educational qualification: all level; working as a farmer for more than one year; farmers present during data collection and willing to participate.

\section{Exclusion Criteria:}

Any type of postural deformities; any history of recent injury/trauma or accident; spinal surgery or any other surgery in any part of the body; any neurologic disorder; limb length discrepancies or any lower limb deformities; retired farmers; pregnant and severely ill farmers.

Informed consent was obtained from the participants. The study was approved by the Municipalities of the Bhaktapur district. Nordic musculoskeletal questionnaire (NMQ) was selected. NMQ Nepali translation was done using forward and backward translation method. Face and content validity was established for the Nepali version of NMQ. In very explicit and simple terms respondents were asked if they had experienced any musculoskeletal discomfort in any of the joints in their body which prevented them from performing the normal activity during the past 12 months or for a short and temporary period of 7 days. ${ }^{19}$ Compilation of the responses was aided by an illustrative body map to indicate the major nine symptom sites - neck, shoulder, upper back, elbow, low back, wrist/hands, hip/thighs, knees, and ankles/ feet. 500 questionnaires were distributed out of which $\mathrm{n}=246$ questionnaires which were returned were found eligible for the study.

\section{Results}

The descriptive statistical analysis of data $(\mathrm{N}=246$, Farmers), showed that the mean age was $46.44 \pm$ 10.92 years. Figure 1 shows the musculoskeletal disorders in all 9 body regions mentioned in NMQ.

Body region-wise analysis of weekly (short-term) and yearly (chronic) prevalence of musculoskeletal discomforts was more common in the neck, shoulder, elbow, low back, knee, and ankle/feet(Table 1). 


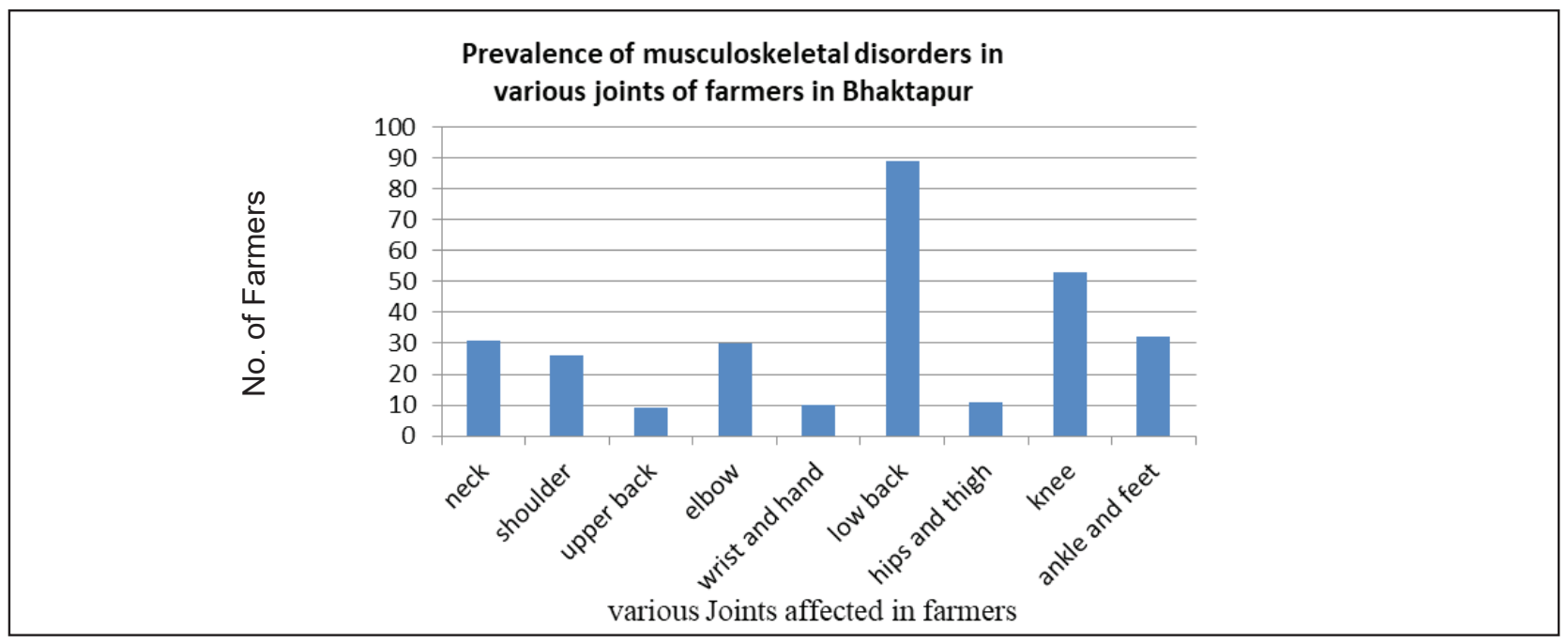

Figure 1: Prevalence of musculoskeletal disorders in various joints.

Table 1: Six major areas of musculoskeletal discomforts found in farmers of Bhaktapur district.

\begin{tabular}{lccc}
\hline Prevalence of MSDs & Response & Frequency $(\mathbf{n})$ & Percentage (\%) \\
\hline Pain in Neck & Yes & 31 & 12.6 \\
Pain in Shoulder & Yes & 26 & 10.6 \\
Pain in Elbow & Yes & 30 & 12.2 \\
Pain in Low back & Yes & 89 & 36.2 \\
Pain in Knee & Yes & 53 & 21.5 \\
Pain in Ankle \& feet & Yes & 32 & 13 \\
\hline
\end{tabular}

\section{Discussion}

Nepal is known as an agricultural country in the world. The statistics show that more than $66 \%$ of its population involve in farming. ${ }^{20}$ Musculoskeletal disorders and the accompanying pain in farmers are multifactorial phenomena. Any part of the body is prone to developing such pain due to the work setup they are in and the nature of the work. Farmers in Nepal especially Bhaktapur district work in vegetable fields and do a lot of manual labor. They also don't have knowledge of ergonomics which makes them susceptible to workrelated MSDs. In the present study, farmers presented with pain in all the nine areas of the body identified in the NMQ. However, some six areas were identified as most common musculoskeletal disorders areas- Low back pain (36.2\%), Knee pain (21.5\%), Ankle and feet pain(13\%), neck pain (12.6\%), elbow pain $12.2 \%)$, shoulder pain $(10.6 \%)$.

There are many types of research which document the prevalence of various musculoskeletal discomfort in an occupation like mine workers, stone cutters, sanitary workers, military personnel, aircrew workers, shoe factory workers, goldsmiths, etc. ${ }^{17}$ But much less has been documented about musculoskeletal discomfort in farmers of Nepal. As the occupational exposure in farming is quite different from other physically demanding occupations, the results of those studies could not be generalized to the farmers, as evident from findings in this study.

Some ergonomic problems of farmers are twisting, bending, manual material handling, awkward postures, lifting, carrying heavy loads, hand tools, work-rest schedule and also lack of training of workers. ${ }^{3,5,21}$ Such risk factors are associated with various musculoskeletal disorders. The risk of slipping, tripping, and fall on uneven fields is also associated with farming and these could also lead to the development of musculoskeletal discomfort in farmers. ${ }^{8,22,23}$ In a study done by Holmberg et al, farmers reported significantly more hand and forearm problems, low back pain and hip problems than non-farmers, and tended to have more neck and shoulder and knee problems. ${ }^{21}$

As farmers in Nepal work in fields manually, they tend to develop symptoms in the shoulder like tendinitis in shoulder ligaments or subacromial bursitis and elbow like tennis elbow or golfers elbow. As they have to bend and squat often so problems in knee and back are also very common. Activities like squatting involve eccentric 
contraction of quadriceps muscles group. A report on agriculture health by Wisconsin University reported that eccentric contraction leads to non-uniform lengthening of the sarcomere. Many other studies have observed more ultrastructural abnormalities in eccentric contraction groups but not in concentric, isometric contraction or passive stretch groups. ${ }^{24}$ This assuming of repetitive and prolonged squatting posture could possibly explain the development of knee pain. Traditional practices in farming are done so plantar fasciitis and ankle pain is the next most common type of disorder involving ankle and feet.

Blinding of the investigation was not done. Data collection was not done using random sampling methods. Bigger sample size could be more representative.

Future research could be done at the national level. Other outcome measures like psychological factors could be incorporated.

\section{References}

1. ILO. ILO Safety and health in agriculture: ILO code of practice. Geneva: ILO; 2011.

2. London L, Nell V, Thompson ML, Myers JF. Health status among farm workers in the Western Cape-collateral evidence from a study of occupational hazards.S Afr Med J. 1998 Sep;88(9):1096-101.

3. Naeini HS, Karuppiah K, Tamrin SB, Dalal K. Ergonomics in agriculture: An Approach in Prevention of Work-related Musculoskeletal Disorders (WMSDs). Journal of Agriculture and Environmental Sciences. 2014 June;3(2):33-51.

4. Heikkonen J, Louhevaara V. Empowerment in farmers' occupational health service. Ann Agric Environ Med. 2003;10:45-52.

5. Parekh SK, Pathak NR. A comparative study between ergonomic advices versus ergonomic plus physiotherapy intervention in Low back pain among farmers. Int J Physiother Res. 2014;2(5):719-24.

6. World Health Organization \& United Nations Environment programme. Public health impact of pesticides used in agriculture. Geneva: World Health Organization; 1990.

7. Vyas R. Ergonomic Assessment of Prevalence of Musculoskeletal Disorders among Indian Agricultural Workers. J Ergonomics JER. 2014;S4:005.

8. El Batawi MA. Health of Workers in agriculture. Cairo: World Health Organization, Regional Office for the Eastern Mediterranean; 2003.

9. Osborne A, Blake C, McNamara J, Meredith D, Phelan J, Cunningham C. Musculoskeletal disorders

\section{Conclusions}

The prevalence of MSDs in farmers is very high. More than $70 \%$ of farmers have some kind of MSDs. Lack of awareness about the MSDs and improper knowledge of ergonomics causes the problems. Many of the musculoskeletal disorders could be avoided by proper use of body mechanics while working. In other words, knowledge or training about ergonomics would be beneficial to the farmers. Knowledge also about the disease would help farmers to apply some precautionary measures or practice therapeutic exercises which would not make the acute problems chronic. Acute pain has mostly converted to chronic pain because of lack of awareness about the disorder. Low back pain is the most common type of MSD followed by knee, ankle, neck, elbow, and shoulder. There is an urgent need for a similar study at a larger scale.

among Irish farmers. Occup Med (Lond). 2010 Dec;60(8):598-603.

10. Gupta G, Tarique. Prevalence of Musculoskeletal disorders in Farmers of Kanpur Rural, India. J Community Med Health Educ. 2013;3:7.

11. Ghasemkhani M, Mahmudi E, Jabbari $H$. Musculoskeletal Symptoms In Workers. International Journal of Occupational Safety and Ergonomics. 2008;14:4:455-62.

12. Dul $J$ and Weerdmeester B. Ergonomics for Beginners. United States: CRC Press; 2001.

13. Kumar S. Perspectives in Rehabilitation Ergonomics. United States: CRC Press; 2005.

14. Kar SK, Dhara PC. An evaluation of musculoskeletal disorder and socioeconomic status of farmers in West Bengal, India. Nepal Med Coll J. 2007;9:245-49.

15. Bihari V, Kesavachandran C, Pangtey BS, Srivastava AK, Mathur N. Musculoskeletal pain and its associated risk factors in residents of National Capital Region. Indian J Occup Environ Med. 2011;15:59-63.

16. Allison TR, Symmons DP, Brammah T, Haynes $P$, Rogers $A$, et al. Musculoskeletal pain is more generalised among people from ethnic minorities than among white people in Greater Manchester. Ann Rheum Dis. 2002;61:151-56.

17. Birabi BN, Dienye PO, Ndukwu GU. Prevalence of low back pain among peasant farmers in a rural community in South Nigeria. Rural Remote Health. 2012;12:1920.

18. Taechasubamorn P, Nopkesorn T, Pannarunothai S. Prevalence of low back pain among rice farmers in 
a rural community in Thailand. J Med Assoc Thai. 2011;94:616-21.

19. Crawford JO. The Nordic Musculoskeletal Questionnaire. Occupational medicine. 2007;57:30001.

20. Pandey $\mathrm{H}$, and Pandey $\mathrm{PR}$, Socio economic development through agro tourism: A case study of Bhaktapur, Nepal, The Journal of Agriculture and environment. 2011;12:59-66.

21. Holmberg S, Stiernström EL, Thelin A, Svärdsudd K. Musculoskeletal symptoms among farmers and non-farmers: a population-based study. Int J Occup Environ Health. 2002 Oct-Dec;8(4):339-45.
22. Holmberg S, Thelin A, Stiernström EL, Svärdsudd K. Low back pain comorbidity among male farmers and rural referents: a population-based study. Ann Agric Environ Med. 2005;12:261-68.

23. Kolstrup CL. Work-related musculoskeletal discomfort of dairy farmers and employed workers. J Occup Med Toxicol. 2102;7:23.

24. Sesto M. Chronic Musculoskeletal Disorders in Agriculture for Partners in Agricultural Health. Madison: Partner in agricultural health Module VIII, University of Wisconsin. 